\title{
Atitudes de Adolescentes Frente à Delinqüência como Representações Sociais
}

\author{
Maria Suzana De Stefano Menin 123 \\ Universidade Estadual Paulista, Presidente Prudente
}

\begin{abstract}
Resumo
Esta pesquisa apresenta a avaliação de 18 infrações que 480 adolescentes realizaram numa escala de 6 pontos. Análises de correspondência entre as formas de avaliar as infrações e várias características da amostra evidenciaram que os meninos, os adolescentes de escolas particulares e os de melhor renda tenderam a avaliar as infrações com mais notas médias que altas e atribuíram às infrações que ameaçam a vida humana as notas mais altas. As meninas, os adolescentes de classes sociais mais baixas tenderam a atribuir notas mais altas a todas as infrações, avaliando-as mais severamente. Os dados foram discutidos com base na teoria de Representação Social.

Palavras-chave: Representações sociais; atitudes de adolescentes; avaliação de infrações.
\end{abstract}

\section{Teenagers's Attitudes of Delinquency as Social Representations}

\begin{abstract}
This work presents the evaluation of 18 infringements that 480 teenagers carried out in six-point a scale correspondence analysis revealed that boys, teenagers of private schools and those of highest income have a tendency to evaluate the infringements with more average marks than high marks and atribute the highest marks to the infringements that threaten human life. Girls, lower class teenagers have a tendency to atribute higher marks to all infringements, evaluating them more severely. Data were discussed taking into account the Theory of Social Representation (Moscovici, Jodelet, Doise).

Keywords: Social representation; evaluation of infringements; teenager's attitude.
\end{abstract}

O que adolescentes consideram como muito errado? Qual seria, para eles, uma infração muito grave? Avaliações morais do que é certo ou errado podem ser vistas na Psicologia como fruto de julgamentos baseados em formas específicas de raciocínio que evoluem em estágios de desenvolvimento moral (Kohlberg, 1992; Piaget, 1932/1977); mas podem, também, ser vistas como representações sociais comuns a indivíduos de um mesmo agrupamento, fruto de determinadas práticas e ancoradas em características sociais e culturais específicas a certos contextos (Doise, 1994; Jodelet, 1994; Moscovici, 1978).

Dentro de uma perspectiva de Psicologia Cognitiva e do Desenvolvimento, são bastantes conhecidos os estudos que Piaget $(1932 / 1977)$ realizou sobre como crianças avaliam roubos, descuidos ou mentiras em pequenas histórias. $\mathrm{O}$ que se constatou é que quanto menor a criança, desde

\footnotetext{
${ }^{1}$ A presente pesquisa é parte da tese de Livre-docência Representaçoes Sociais de Lei, crime e injustiça em adolescentes; Menin, M. S. S. Faculdade de Ciências e Tecnologia, UNESP; Presidente Prudente.

${ }^{2}$ Agradecemos à FUNDUNESP o auxílio para a apresentação deste trabalho no Congresso Internacional de Valores Universais e o Futuro da Sociedade - SP e na II Jornada Internacional sobre Representações Sociais - SC/2001. ${ }^{3}$ Endereço para correspondência: Rua Roberto Simonsen, 305; Cx.Postal 957, 19060 900, Presidente Prudente, SP. E-mail: menin@prudente.unesp.br
}

que capaz de representar e emitir julgamentos, mais seus julgamentos ocorrem em função das conseqüências aparentes dos atos e menos em função das intenções. Inversamente, quanto mais velha a criança e desde que possa ter vencido seu egocentrismo em relações sociais cooperativas, mais flexível será seu julgamento das infrações passando a pesar todos os atenuantes de um ato em função das intenções.

As formas como crianças consideram errôneas e puníveis certas ações também variam, segundo Piaget (1932/1977) conforme o desenvolvimento infantil. Quanto menores as crianças pré-operatórias, mais rígidas em seus julgamentos, considerando toda a infração como punível com castigos arbitrários e severos - sanção de expiatória. Por outro lado, quanto maior a criança, mais poderá usar outro tipo de sanção, a por reciprocidade, baseada na idéia de reconstrução das relações sociais e de reconstituição dos estragos ou reposição dos danos causados.

As diferenças da forma de julgamento das crianças mais novas em comparação às mais velhas, se explicam, para Piaget, em função, do desenvolvimento cognitivo e, sobretudo, das formas de relações sociais vividas: quanto maior a participação das crianças em relações sociais de cooperação que envolvem a necessidade de considerar as necessidades dos outros, de discutir e combinar decisões nos grupos que envolvam 
indivíduos com diferentes pontos de vista, mais haverá descentrações intelectuais, sociais e morais e mais as crianças poderão melhor julgar os atos de outros, suas "infrações". Por outro lado, quanto mais a criança se mantiver em relações sociais de coerção onde a troca entre iguais for impedida e intermediada pelo mais forte, mais ela ficará trancafiada em seu egocentrismo e, simultaneamente, presa aos padrões de julgamento do mais velho (mais forte) numa repetição acrítica de seus valores.

Bastante conhecidos, também, são os trabalhos de Kohlberg (1992) sobre julgamentos de dilemas morais e que deram continuidade à pesquisa piagetiana sobre desenvolvimento do juízo moral. A severidade ou rigidez dos julgamentos será diferente, conforme os níveis de raciocínio moral pré-convencional, convencional e pósconvencional. De acordo com as características destes níveis pode-se esperar que no pré-convencional serão julgados como mais errados aqueles atos sabidamente proibidos, facilmente descobertos e, portanto, puníveis. No nível convencional, serão mais errados os atos que assim forem concebidos pelas autoridades e pelas convenções mais conhecidas; provavelmente, nesse nível, também serão considerados como mais errados os atos que perturbarem a ordem social. No nível pós-convencional, em função primeiramente da preocupação com o que foi contratado socialmente, serão errados os atos que prejudicarem os interesses acordados da maioria das pessoas e que quebrarem o que foi estabelecido como justo e certo pela maior parte dos envolvidos. Além disso, no estágio seis, seria de se esperar que fossem considerados como mais errados os atos que ameaçassem os princípios mais básicos orientadores da vida humana, entre eles, a vida e a dignidade de qualquer ser humano; os quais deveriam ser respeitados não por temor, convenção ou interesses particulares, mas, porque só eles garantem que nenhum ser humano seja usado como meio para os interesses de qualquer outro.

Embora possam existir variações individuais e grupais na severidade e formas de julgamento condenatórios, para os autores anteriores, as avaliações morais aparecem em estágios de desenvolvimento, hierarquizados, de seqüência invariável, de presença universal e que se constróem em correspondência ao desenvolvimento cognitivo e social.

$\mathrm{Na}$ perspectiva das representações sociais atitudes positivas ou negativas a infrações consideradas atos delinqüentes, assim como o próprio conceito sobre o que é delinqüência, podem variar entre grupos, não por representarem formas mais "adiantadas" ou "atrasadas" de desenvolvimento cognitivo e moral, mas por terem uma construção coletiva, marcada por práticas sociais, pela história e cultura comuns a determinados grupos de pessoas e servindo, assim, de referenciais de mundo.
Prenunciando esse referencial estão os estudos de Malewska, Peyre e Bonerandi (1979) e Maleswka e Walgrave (1983) sobre delitos de jovens e julgamento social e que consideram valores como fruto de representações sociais que os adolescentes de diferentes grupos fazem sobre a delinqüência.

Maleswska e colaboradores (1979) compararam na França a avaliação de 25 infrações que diferentes grupos de leigos ou profissionais que lidam com a delinqüência fizeram. Os grupos foram: juizes, educadores e assistentes sociais, policiais, menores infratores, pais, estudantes de escolas técnicas e de liceus. ${ }^{3}$ Mais tarde, Maleswska e Walgrave (1983) compararam essas populações com outras semelhantemente obtidas em dois outros países, a Bélgica e a Polônia. Os autores afirmaram que a delinqüência é, em parte, algo definido pela cultura; além disso, supuseram que as atitudes sobre a delinqüência dependem do lugar social do sujeito que as considera. Considerando as atitudes como disposições relativamente duráveis em relação a um objeto determinadas por um conjunto de elementos cognitivos e emocionais a ele ligados, os autores acreditam que elas mudam conforme o conhecimento e o envolvimento emocional dos sujeitos; assim, é de se esperar que jovens infratores, pais, educadores de menores, juizes ou policiais façam avaliações diferentes sobre o que é considerado infração.

Para comparar diferentes amostras de pessoas dos três países, França, Bélgica e Polônia e de diferentes profissões (foram mais de 2000 pessoas, nos dois estudos), foi utilizada uma lista de 25 infrações. Cada infração da lista deveria ser avaliada numa escala de sete pontos quanto à gravidade. Malewska e Walgrave (1983) entenderam que a avaliação de infrações através de uma escala provoca um pré-julgamento moral-afetivo no qual cada pessoa faz uma síntese subjetiva de todo um sistema formal e informal de valores existentes; além disso, as atitudes aí explicitadas marcam certas tendências de ação e mesmo que essa relação não seja direta, ela é importante para prever e explicar certas posições dos profissionais que trabalham com a delinqüência.

Como resultados mais gerais, tanto na primeira pesquisa (Maleswska \& cols., 1979) como na segunda (Malewska \& Walgrave, 1983) os autores obtiveram que todas as populações pesquisadas avaliaram com mais gravidade atos que envolviam violência física às vítimas. Delitos como roubos sem agressão e infrações sem vítimas individuais

\footnotetext{
${ }^{3}$ A lista envolveu infrações como: destruir uma cabine telefônica, fugir de um acidente que provocou, roubar discos, bebidas, bicicleta, pedir esmolas, falsificar carta de identidade, maltratar um animal, bater na mãe, assaltar, prostituir-se, abortar, usar maconha, fazer chantagem, maltratar uma criança, incendiar uma granja, fazer amor em lugar público, roubar com uso da força, receber coisas roubadas.
} 
foram julgados mais indulgentemente. No entanto, a dispersão na forma de atribuir notas altas ou baixas e a severidade ou indulgência dos julgamentos variou conforme os grupos de respondentes. Por exemplo, em todas as populações, considerando os três países, foi entre os menores da justiça que se obteve mais indulgência nos julgamentos de infrações mais graves e maior dispersão nas respostas, isto é, onde se usavam notas ou muito altas ou muito baixas e foi entre os juizes que se obteve mais consenso, portanto, menor dispersão. Ao compararem os adolescentes oriundos de classes sociais baixas - escolas técnicas e mais altas liceus, verificou-se que, mesmo entre países diferentes, quanto maior o nível sócio-econômico mais os jovens usavam a escala em todas as suas possibilidades, eram menos severos para infrações ligadas a roubos e atos marginais e mais severos para infrações ligadas à violência física e ameaça à vida. Quanto ao rigor no uso de notas altas dos estudantes de escolas técnicas os autores concordaram com a posição de Podgorecki (1971, citado em Malewska \& cols., 1979) de que quanto mais difíceis a adaptação dos jovens ao meio social e sua situação social, maior é sua tendência a avaliações rigorosas. Quanto aos menores infratores, os autores supuseram que suas atitudes refletem uma revolta contra os julgamentos formais e informais a que foram submetidos e as instituições em que foram colocados. Para manter uma imagem positiva de si, esses adolescentes seriam mais indulgentes com as infrações que eles possam ter cometido. Quanto aos jovens das escolas técnicas os autores se perguntaram se suas posições rígidas seriam devidas a uma maior interiorização da moral tradicional e de uma forte vontade de se distinguir dos infratores. Essa questão não foi respondida embora tenha-se sugerido que nas respostas desses adolescentes apareceu um imagem de delinqüência fortemente calcada naquelas divulgadas em filmes policiais e nos meios de comunicação de massa, principalmente a imprensa sensacionalista. Os autores concluem afirmando que não se pode falar da existência de uma única representação de delinqüência ou de atitudes comuns a ela; ao contrário há diversidades nesses elementos que se explicariam principalmente por dois fatores: por um lado, as práticas profissionais que influem e modelam atitudes e representações e, por outro lado, as ideologias predominantes e os valores morais presentes na cultura de diferentes países e grupos sociais.

De forma semelhante e mais atualmente, destacam-se os trabalhos de Doise sobre Direitos Humanos e que tratam valores como representações sociais (Doise, 1991; Doise, Clémence, de Rosa \& Gonzales, 1995). Considerar direitos humanos como representações sociais, implica em entendêlos como um corpo de conhecimentos comuns a grupos de pessoas e que podem ter relações mais ou menos diretas com a Declaração dos Direitos Humanos de 1948, a forma mais sistematizada historicamente em que esses direitos foram apresentados. Implica, também, em buscar identificar os princípios organizadores das representações desses direitos, isto é, as idéias ou direções das mesmas que as organizam como conhecimentos e que podem ser próprias de um conjunto de pessoas mais ou menos amplo; e, ainda, em identificar as ancoragens desses princípios em variáveis diversas como as origens sociais dos grupos que as possuem, suas características culturais e/ou históricas, suas posições sobre outras idéias que se relacionam aos direitos humanos. Considerando a ancoragem como a incorporação do novo ou desconhecido num conjunto de categorias familiares a um grupo social (Doise, 1994) assume-se como hipótese, nessa abordagem, que o que as pessoas de diferentes profissões, status sociais, sociedades ou países, consideram como direitos humanos pode variar em função de suas pertinências sociais e de como esses direitos tem sido divulgados e vivenciados nos seus espaços sociais.

Um exemplo dessa investigação é a pesquisa que Doise e colaboradores (1995) realizaram em quatro países - França, Suíça, Costa Rica e Itália, tendo como participantes quase mil jovens entre 13 a 20 anos. Dentre outras questões pediram aos jovens que, numa lista de 21 proposições indicassem, numa escala de gravidade, quais seriam atentados aos direitos humanos. Como principais resultados os autores encontraram, em primeiro lugar, um forte consenso no que foi considerado como um atentado aos direitos humanos: as infrações ao direito de defesa, as ameaças à integridade física das pessoas (o maltrato infantil pelos pais foi a segunda ação mais considerada um atentado aos direitos humanos por todos os países), a desigualdade racial, as ameaças às liberdades de expressão. Em outras esferas esse consenso foi menor, como por exemplo a que se referiu à extensão do domínio da família sobre os indivíduos. Ao verificarem as ancoragens das representações sociais dos direitos humanos, Doise e colaboradores (1995) mostraram que essas representações variaram em função dos contextos nacionais, de características sociais e das posições dos jovens em outros domínios, como a extensão que atribuíram controles individuais ou governamentais aos direitos. Os contextos nacionais tiveram um impacto sobre as representações bem mais importante que as demais variáveis. Houve, por exemplo, uma oposição entre a Itália e os outros países; os italianos deram uma definição bem mais ampla dos direitos humanos, incluindo os problemas de relações familiares que não foram tão considerados pelos outros países e aderiram menos a outros direitos relacionados à liberdade de religião ou de expressão.

Em síntese, podemos concluir que os trabalhos de Doise e sua equipe demonstram que algo que se poderia pensar como universal, como os direitos fundamentais aos seres 
humanos ou o que se considera um atentado a esses direitos organiza-se diferentemente, conforme certas pertinências sociais. Essas, por sua vez, trazem para a construção das representações diferentes culturas, histórias e formas de viver o que se considerou como direitos humanos.

Recentemente, foi utilizada uma escala inspirada nos trabalhos anteriormente citados (Doise \& cols., 1995; Malewska \& cols., 1979; Malewska \& Walgrave, 1983) com adolescentes chamados à promotoria pública por terem se envolvido em atos considerados infracionais (Menin, 2000a). Embora tenham sido entrevistados apenas 20 jovens de diferentes idades, os dados obtidos confirmaram algumas das tendências já encontradas. As infrações tidas como mais graves foram as relacionadas à violência física, embora sigam, muito de perto, outras ligadas ao consumo de drogas e roubos diversos. As infrações consideradas mais leves foram ligadas a vandalismo, à violência contra um animal (que na França, na Bélgica e na Polônia foi considerada como uma infração grave), ao uso de falsa identidade e direção sem carta. É curioso que duas infrações envolvendo a violência física tenham sido consideradas pouco graves: matar um menino que vivia assaltando e um policial ferir alguém que ele tentava prender. Dessa forma, a violência contra as pessoas e mesmo contra as crianças não apareceu como um claro e forte "contra-valor" em nossos entrevistados; ou seja, a integridade física não parece ser um valor tão "sagrado" para os jovens entrevistados no Brasil (Menin, 2000a) como os jovens europeus nos estudos de Malewska e Walgrave (1983) ou de Doise e colaboradores (1995).

Considerando essa perspectiva mais social em que se podem analisar as avaliações sobre infrações, passamos a apresentar a pesquisa que realizamos com adolescentes com o objetivo de identificar como tais jovens avaliam infrações e se estas diferem significativamente em função das pertinências sociais dos mesmos.

\section{Método}

Adolescentes de 11 escolas públicas e três escolas particulares de Presidente Prudente, cidade do interior de Estado de São Paulo, responderam a um questionário (no total de 478) que, entre outras questões abertas e fechadas sobre leis e justiça (apresentadas em Menin, 2000b), continha uma escala de 18 infrações. Os adolescentes deveriam marcar, entre seis notas $(0,2,4,6,8,10)$ e para cada infração, aquelas que considerassem nada graves (nota 0 ) a aquelas que considerassem muito graves (nota 10).

Os alunos pertenciam, em sua maioria, à oitava série do Ensino Fundamental e à primeira do Ensino Médio e concentraram-se na faixa etária de 15 anos. A amostra foi equilibrada em termos de sexo masculino e feminino. Entre os estudantes das escolas particulares, $92 \%$ dos alunos não trabalhavam fora, $76 \%$ tinham pais em profissões de nível superior e/ou chefias, $86 \%$ de suas famílias tinham renda superior a 10 salários mínimos, 87\% moravam em bairros de alta e média inclusão social. Dentre os alunos das escolas públicas, 33\% trabalhavam fora, $86 \%$ tinham pais em profissões de nível médio ou inferior em termos salariais e de formação (Ex.: ajudantes, auxiliares), 80\% das famílias tinham renda salarial inferior a 10 salários mínimos e $62 \%$ habitavam em bairros de média e alta exclusão social.

As infrações utilizadas foram as seguintes, apresentadas nesta ordem:

"1- um policial fere alguém que ele tentava prender; 2matar alguém numa briga; 3-dirigir sem carta; 4- destruir uma carteira escolar; 5- usar maconha; 6- usar a carteira de identidade de outra pessoas para entrar numa danceteria que exige 16 anos; 7- xingar a professora; 8usar craque ou cocaína; 9- agredir fisicamente um colega; 10- maltratar uma criança; 11- uma adolescente se prostituir; 12- fazer um aborto; 13- matar uma pessoa para roubar o seu dinheiro; 14- cortar com estilete o banco de um ônibus; 15-roubar um blusão de uma grande loja; 16- matar um menino de quinze anos que vivia na rua assaltando os outros; 17-furtar o toca-fitas de um carro estacionado na rua; 18 - riscar a pintura de um carro com prego."

As ações, nas infrações, foram propositadamente descritas sucintamente e esperávamos com elas obter um primeiro posicionamento dos jovens; dar notas é uma maneira de obter uma quantificação das atitudes positivas ou negativas com relação a algo. Para Moscovici (1978) as representações surgem depois ou em torno das atitudes sobre um objeto e servem para justificá-las; para Doise (1994) "estudar a ancoragem das atitudes nas relações sociais que as geram é estudá-las como representações sociais"'(p. 224)

\section{Resultados}

A pontuação dada às infrações pelos alunos das escolas públicas e particulares

Para podermos comparar as pontuações que os alunos fizeram das infrações obtivemos, em primeiro lugar, uma média das notas dadas à cada infração em relação a subpopulações extraídas da população geral dos 478 alunos respondentes ao questionário (os respectivos desviospadrão estão no Anexo A). Como se pode observar na Tabela 1 as médias das notas foram bastante altas, para a maioria das infrações, sendo o valor mais baixo de 5,17 para a infração sobre um policial ferir alguém. A média mais alta, aproximou-se de $10(9,71)$ e foi dada pelas meninas à infração sobre usar craque e cocaína. 
Tabela 1

Médias de Notas dadas às Infrações pelas Subpopulacõoes de Alunos

Infrações

Usar craque ou cocaína

Matar para roubar

Furtar toca-fitas

Maltratar criança

Roubar blusão de loja

Uma adolescente se prostituir

Matar alguém numa briga

Usar maconha

Fazer aborto

Riscar a pintura de um carro

Destruir carteira escolar

Cortar banco de ônibus

Agredir colega

Xingar professora

Dirigir s/ carta

Matar menino assaltante

Falsificar documento

Policial ferir alguém

\begin{tabular}{|c|c|c|c|c|c|c|c|c|c|}
\hline 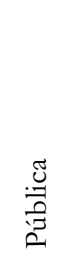 & 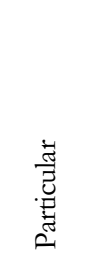 & 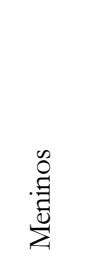 & 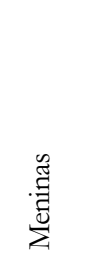 & 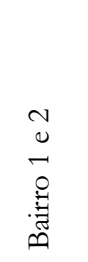 & $\begin{array}{l}+ \\
\tilde{D} \\
\tilde{n} \\
\tilde{\Xi} \\
\stackrel{\Xi}{0} \\
\infty\end{array}$ & 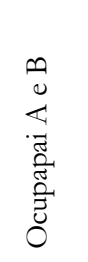 & $\begin{array}{l}0 \\
0 \\
\cup \\
= \\
\tilde{\Xi} \\
\tilde{\Xi} \\
\tilde{J} \\
0\end{array}$ & 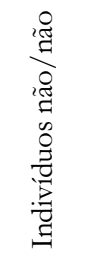 & 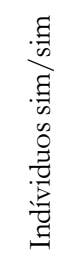 \\
\hline 9,50 & 9,50 & 9,27 & 9,71 & 9,56 & 9,43 & 9,61 & 9,45 & 9,69 & 9,48 \\
\hline 9,43 & 9,60 & 9,22 & 9,70 & 9,50 & 9,40 & 9,71 & 9,38 & 9,31 & 9,55 \\
\hline 9,18 & 9,34 & 9,01 & 9,41 & 9,22 & 9,21 & 9,37 & 9,20 & 9,37 & 11 \\
\hline 9,14 & 9,37 & 9,05 & 9,34 & 9,25 & 9,14 & 9,38 & 9,09 & 9,34 & 9,29 \\
\hline 9,11 & 9,17 & 8,85 & 9,38 & 9,29 & 9,00 & 9,20 & 9,17 & 9,43 & 9,02 \\
\hline 9,05 & 9,13 & 8,62 & 9,47 & 9,24 & 8,89 & 9,04 & 9,07 & 9,37 & 8,96 \\
\hline 9,02 & 9,13 & 8,68 & 9,37 & 9,13 & 9,03 & 9,21 & 9,03 & 9,14 & 9,17 \\
\hline 8,99 & 8,71 & 8,57 & 9,24 & 9,14 & 8,72 & 8,67 & 9,10 & 9,26 & 8,62 \\
\hline 8,70 & 7,36 & 7,90 & 8,78 & 8,72 & 7,96 & 7,23 & 8,66 & 8,57 & 7,65 \\
\hline 8,56 & 8,98 & 8,53 & 8,78 & 8,62 & 8,73 & 8,97 & 8,61 & 9,01 & 8,53 \\
\hline 8,02 & 8,10 & 7,87 & 8,19 & 8,00 & 8,09 & 8,19 & 7,91 & 8,06 & 8,22 \\
\hline 7,94 & 8,47 & 7,87 & 8,26 & 8,02 & 8,13 & 8,43 & 7,95 & 8,20 & 8,31 \\
\hline 7,89 & 8,13 & 7,51 & 8,35 & 7,89 & 7,99 & 8,05 & 7,91 & 8,46 & 7,75 \\
\hline 7,84 & 8,20 & 7,54 & 8,28 & 7,97 & 7,87 & 8,03 & 7,90 & 8,20 & 7,88 \\
\hline 7,61 & 6,81 & 7,00 & 7,77 & 7,89 & 7,00 & 6,79 & 7,50 & 7,59 & 7,01 \\
\hline 7,45 & 8,23 & 7,21 & 8,04 & 7,77 & 7,59 & 7,85 & 7,59 & 7,54 & 7,76 \\
\hline 6,98 & 6,10 & 6,39 & 7,09 & 7,26 & 6,32 & 5,57 & 7,14 & 7,09 & 6,42 \\
\hline 5,50 & 5,39 & 5,21 & 5,71 & 5,80 & 5,17 & 5,36 & 5,51 & 6,00 & 5,45 \\
\hline
\end{tabular}

A partir da Tabela 1, pudemos realizar, tal como Maleska, Bonerandi e Peyre (1979) o fizeram, a Tabela 2 que mostra um rank das infrações nas diferentes subpopulações dos alunos, isto é, como elas aparecem ordenadas, da mais grave, com número 1 , à menos grave, com número 18 , em cada subpopulação. Essa tabela permite uma comparação qualitativa com relação à posição em que as infrações ocupam nas diferentes subpopulações.

A Tabela 2 mostra, do lado esquerdo a seqüência das infrações quando as ordenamos em função das notas que os alunos das escolas públicas deram a cada infração, das mais altas às mais baixas. As colunas representam os alunos subdivididos em subpopulações quanto a tipo de escola, sexo, bairro de residência ( 1 e 2 de alta e média exclusão social e 3 e 4 de alta e média inclusão social ), nível ocupacional dos pais (A e B de chefias, direção e nível superior e $\mathrm{C}$ e $\mathrm{D}$ de nível médio e atividades de produção, ajudantes e auxiliares) e rigidez ou tolerância com relação à possibilidade de modificação das leis e de sua desobediência ${ }^{4}$ (os indivíduos Não/não, que responderam anteriormente que as leis não podem ser mudadas e nunca se pode desobedecê-las; os indivíduos $\mathrm{Sim} / \mathrm{sim}$ que responderam que as leis podem ser mudadas e que existem situações em que é certo desobedecê-las). $\mathrm{Na}$ primeira seqüência do rank, as sete infrações mais graves, com médias superiores a nove, relacionaram-se ao uso de drogas pesadas (usar craque ou cocaína), às que envolveram violência física (matar para roubar e maltratar uma criança), mescladas com furtos simples (furto de um toca-fitas, furto de um blusão); seguiu-se a prostituição e o matar alguém numa briga. Como as menos graves, com notas médias menores que sete, apareceram as infrações relacionadas à falsificação de documento e ao policial ferir alguém que ele tentava prender.

\footnotetext{
${ }^{4}$ Essa classificação foi obtida na primeira parte da pesquisa (Menin, 2000b). Os indivíduos Não/não foram 15\% da amostra estudada (480), sendo que $91 \%$ pertenciam à escola pública e eram de famílias de baixa renda. Os indivíduos Sim/sim foram 29\% de alunos podendo ser de escolas públicas ou particulares.
} 
Tabela 2

Rank das Notas às Infrações nas Subpopulações dos Alunos

Infrações

Usar craque ou cocaína

Matar para roubar

Furtar toca-fitas

Maltratar criança

Roubar blusão de loja

Uma adolescente se prostituir

Matar alguém numa briga

Usar maconha

Fazer aborto

Riscar a pintura de um carro

Destruir carteira escolar

Cortar banco de ônibus

Agredir colega

Dirigir s/ carta

Matar menino assaltante

Falsificar documento

Policial ferir alguém
Xingar professora

\begin{tabular}{|c|c|c|c|c|c|c|c|c|c|}
\hline $\begin{array}{l}\stackrel{\mathscr{U}}{0} \\
\overline{0}\end{array}$ & 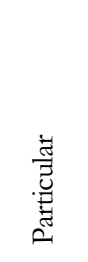 & 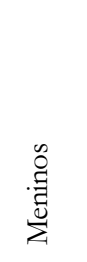 & 胥 & 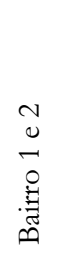 & $\begin{array}{l}\tilde{J} \\
\tilde{n} \\
\tilde{n} \\
\ddot{g} \\
\tilde{n}\end{array}$ & 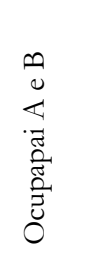 & 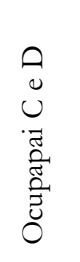 & 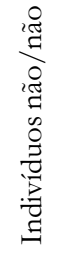 & 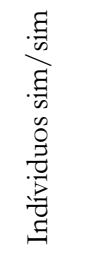 \\
\hline 1,0 & 2,0 & 1,0 & 1,0 & 1,0 & 1,0 & 2,0 & 1,0 & 1,0 & 2,0 \\
\hline 2,0 & 1,0 & 2,0 & 2,0 & 2,0 & 2,0 & 1,0 & 2,0 & 6,0 & 1,0 \\
\hline 3,0 & 4,0 & 4,0 & 4,0 & 6,0 & 3,0 & 4,0 & 3,0 & 3,5 & 5,0 \\
\hline 4,0 & 3,0 & 3,0 & 7,0 & 4,0 & 4,0 & 3,0 & 6,0 & 5,0 & 3,0 \\
\hline 5,0 & 5,0 & 5,0 & 5,0 & 3,0 & 6,0 & 6,0 & 4,0 & 2,0 & 6,0 \\
\hline 6,0 & 7,0 & 7,0 & 3,0 & 5,0 & 7,0 & 7,0 & 7,0 & 3,5 & 7,0 \\
\hline 7,0 & 6,0 & 6,0 & 6,0 & 8,0 & 5,0 & 5,0 & 8,0 & 8,0 & 4,0 \\
\hline 8,0 & 9,0 & 8,0 & 8,0 & 7,0 & 9,0 & 9,0 & 5,0 & 7,0 & 8,0 \\
\hline 9,0 & 15,0 & 10,0 & 10,0 & 9,0 & 13,0 & 15,0 & 9,0 & 10,0 & 15,0 \\
\hline 10,0 & 8,0 & 9,0 & 9,0 & 10,0 & 8,0 & 8,0 & 10,0 & 9,0 & 9,0 \\
\hline 11,0 & 14,0 & 11,0 & 14,0 & 12,0 & 11,0 & 11,0 & 13,0 & 14,0 & 11,0 \\
\hline 12,0 & 10,0 & 12,0 & 13,0 & 11,0 & 10,0 & 10,0 & 11,0 & 12,5 & 10,0 \\
\hline 13,0 & 13,0 & 14,0 & 11,0 & 14,0 & 12,0 & 12,0 & 12,0 & 11,0 & 4,0 \\
\hline 14,0 & 12,0 & 13,0 & 12,0 & 13,0 & 14,0 & 13,0 & 14,0 & 12,5 & 12,0 \\
\hline 15,0 & 16,0 & 16,0 & 16,0 & 15,0 & 16,0 & 16,0 & 16,0 & 15,0 & 16,0 \\
\hline 16,0 & 11,0 & 15,0 & 15,0 & 16,0 & 15,0 & 14,0 & 15,0 & 16,0 & 13,0 \\
\hline 17,0 & 17,0 & 17,0 & 17,0 & 17,0 & 17,0 & 17,0 & 17,0 & 17,0 & 17,0 \\
\hline 18,0 & 18,0 & 18,0 & 18,0 & 18,0 & 18,0 & 18,0 & 18,0 & 18,0 & 18,0 \\
\hline
\end{tabular}

É interessante notar como o uso de drogas pesadas foi pontuado da forma a mais severa entre os alunos. Das dez subpopulações que traçamos, só em três essa infração não apareceu em primeiro lugar, sendo suplantada por matar para roubar pelos alunos das escolas particulares, ou entre aqueles com pais em profissões de alto status e salário e entre os indivíduos tolerantes. ${ }^{5}$ Pensamos que pode ter se dado, nesta pesquisa, o mesmo que numa anterior (Menin, 2000a): os alunos acreditam que as drogas pesadas são um veículo para a morte, tanto de si próprios como de outros.

A segunda infração colocada como mais grave em quase todas as populações foi a ação de matar para roubar, o que mostra que a valorização da vida humana é, de certa forma, um consenso, o que seria de se esperar, também, dentro da teoria de Kohlberg. No entanto, veremos que esse valor se torna relativo quando a vida é de um elemento considerado malfeitor, como o menino que assalta os outros na rua. Nesse caso, matar parece se justificar para grande parte de

\footnotetext{
${ }^{5}$ É preciso cuidado nas comparações entre as subpopulações; como são sempre os mesmos alunos é correto que façamos as comparações sempre dentro dos pares separados de acordo com o mesmo critério.
}

nossos alunos que colocaram essa infração como a terceira ou quarta menos grave!

Quando se observam as colunas da Tabela 2 comparando-se os pares de subpopulações quanto a tipo de escola, sexo, bairro de residência, ocupações dos pais e indivíduos "rígidos"(Não/não) e "tolerantes"(Sim/sim) notam-se diferenças qualitativas interessantes nas posições que as infrações ocupam no rank. Nas escolas particulares, por exemplo, houve uma inversão quanto ao lugar das infrações relacionadas à violência física: matar para roubar está em primeiro lugar, maltratar uma criança está na frente de roubar um blusão de uma loja, matar alguém numa briga foi considerado mais grave que a prostituição, e matar um menino assaltante passou do décimo sexto lugar na escola pública ao décimo primeiro na escola particular, sendo, portanto, neste tipo de escola, considerado mais grave que xingar a professora, agredir um colega, destruir uma carteira escolar e fazer um aborto. Tais variações nos fazem supor que a integridade física, como um valor, aparece diferentemente para os alunos das escolas particulares e públicas; nas primeiras, seria um valor mais forte que nas segundas onde furtar um toca-fitas é mais grave que maltratar 
uma criança ou matar um menino assaltante é menos grave que dirigir sem carta. Quanto ao aborto, vemos que ocupa um lugar muito diferente nas escolas públicas, nono lugar entre as mais graves e, nas particulares, o décimo quinto, sendo, portanto, considerada uma infração das menos graves.

Quando comparamos meninos e meninas também notamos certas diferenças na ordenação das infrações. Curiosamente, maltratar uma criança passou do terceiro lugar segundo as notas dadas pelos meninos ao sétimo lugar quando se olha o rank das meninas. Não sabemos dizer se isso se deu pelas meninas pensarem como certos jovens entrevistados em outra pesquisa (Menin, 2000a), que diziam que "se as crianças apanharam é porque alguma coisa fizeram"... Inversamente, a prostituição foi julgada de forma bem mais severa pelas meninas ficando em terceiro lugar entre as infrações mais graves. Quando comparamos as agressões mais leves às pessoas com os atos de vandalismo sobre coisas públicas vemos, também, uma inversão entre meninos e meninas; os primeiros consideraram a agressão a um colega e o xingar a professora como menos graves que destruir uma carteira escolar e cortar o banco de um ônibus, as meninas avaliaram o contrário: consideraram as agressões às pessoas como mais graves que às coisas.

Comparando-se os bairros de residência dos alunos também constatamos diferenças nas posições das infrações no rank da Tabela 2 entre os alunos de bairros 1 e 2 de alta e média exclusão social e 3 e 4, de média e alta inclusão social. Furtar o toca-fitas de um carro e roubar um blusão de uma grande loja ocuparam lugares opostos entre as duas subpopulações de alunos; entre os de bairros mais pobres roubar um blusão foi bem mais grave que furtar um toca-fitas de carro, entre os alunos de bairros mais ricos foi o inverso. Talvez esses alunos tenham levado em conta que roubar um blusão poderia ocorrer por uma necessidade maior que a que motivaria o roubo de um toca-fitas, e, talvez, como nos exemplos de Malewska e Walgrave (1983) os alunos de bairros pobres tenham sido mais severos que os de bairros mais ricos na busca em diferenciar-se de malfeitores. Outra diferença acentuada ocorreu com relação à infração sobre matar alguém numa briga; entre os alunos de bairros mais pobres essa infração ficou em oitavo lugar enquanto que entre os alunos de bairros mais ricos ficou em quinto lugar; ou seja, de novo, foi entre os alunos de nível social mais alto que a vida das pessoas apareceu como um valor maior. A prostituição e o aborto também foram julgados de modo bem mais severo entre os alunos de bairros mais pobres (pegando o quinto e nono lugares) que entre os de bairros de inclusão social (onde ficaram no sétimo e no décimo terceiro lugar).

As diferenças entre os alunos quando subdivididos em relação às profissões paternas reproduzem, qualitativamente, o sentido das diferenças já observadas entre os mesmos alunos quando subdivididos por tipo de escola e bairros.

Finalmente, as comparações entre os indivíduos rígidos e tolerantes mostram oposições intrigantes. Excetuando-se o uso das drogas pesadas, que ficou em segundo lugar (e que pode confirmar a direção que vemos ao invés de negála) os indivíduos tolerantes pontuaram como as três infrações mais graves as que tiram a vida ou a colocam em risco: matar para roubar, maltratar uma criança e matar alguém numa briga. Foi só nessa subpopulação de alunos, entre os indivíduos tolerantes, ou $\mathrm{Sim} / \mathrm{sim}$, que a ação de matar alguém numa briga, mesmo que podendo ser não intencional foi colocada como tão grave. Esse dado nos faz recorrer a Kohlberg (1992) quando descreveu que, no estágio seis, princípios universais guiam os julgamentos e o valor e a dignidade da vida humana são um deles. Se, de fato, as duas últimas questões sobre as leis mensuraram a presença do nível três de raciocínio legal e moral quando se respondeu a elas afirmando a mutabilidade das leis e a relatividade de sua desobediência em função do bem comum e da moralidade da própria lei, então, a posição dos indivíduos $\mathrm{Sim} / \mathrm{sim}$ foi coerente com esse tipo de raciocínio. Parece que em todas essas situações de julgamento um mesmo princípio organizador estaria presente, como diz Doise (1995) e seria, nesse caso, o do valor da vida humana. Por outro lado, são incompreensíveis os critérios que levaram os indivíduos rígidos, Não/não, a colocar mais notas dez em infrações como roubar um blusão, roubar um toca-fitas e prostituição que maltratar uma criança e que matar para roubar. É como se infrações mais conhecidas e freqüentemente punidas como o uso de drogas, o roubo e a prostituição fossem mais graves que algo mais improvável e distante que o matar para roubar. Se o raciocínio foi esse, então, revela-se um pensamento pré-conceitual de primeiro estágio, tal como descrito por Kohlberg (1992) onde errado é o que leva, mais certamente, à punição. Ainda com relação aos indivíduos Não/não pode se ver o aborto sendo julgado severamente ( $10^{\circ}$ lugar); já entre os indivíduos tolerantes, foi colocado como um das infrações menos graves $\left(15^{\circ}\right.$ lugar). Finalmente, chama a atenção que entre os alunos tolerantes a infração matar um menino assaltante tenha sido colocada em décimo terceiro lugar em gravidade enquanto que entre os alunos rígidos apareceu como a terceira infração menos grave.

Nossas análises parecem confirmar aquelas que Malewska e colaboradores (1979) e Malewska e Walgrave (1983) fizeram entre os alunos de liceu e os de escolatécnica (comércio); também entre eles, os alunos de nível econômico mais baixo foram mais severos em seus julgamentos em geral; e, para certos comportamentos que os alunos de liceu, mais instruídos, consideraram de menor gravidade (principalmente os ligados à propriedade quando 
comparados à dignidade e vida humana) e foram menos indulgentes.

Uma segunda forma de analisar as notas dadas às infrações é considerar a severidade e julgamento das avaliações em função das porcentagens do uso de notas baixas, médias ou altas nas subpopulações de alunos. Alunos muito severos usariam mais notas altas que médias ou baixas, alunos mais indulgentes usariam mais notas baixas e médias que altas. A Tabela 3 mostra a contagem do número de vezes em que as subpopulações usaram notas baixas (valores 0 e 2 na escala) médias (valores 4 e 6 ) e altas (valores 8 e 10) na escala de infrações e essas porcentagens.

$\mathrm{Na}$ Tabela 3 notamos, em primeiro lugar, que foi muito freqüente o uso de notas altas ( 8 e 10) em todas as subpopulações de alunos. Mesmo que as comparações sejam relativas pois as escalas não são idênticas, nossos alunos parecem bem mais severos em seus julgamentos que os franceses, belgas ou poloneses examinados por Malewska e colaboradores (1979) e Malewska e Walgrave (1983). No entanto, as comparações dentro de cada par de subpopulações revelam diferenças significativas e interessantes. ${ }^{6}$ adolescentes. Os alunos de escola particular, por sua vez, usam mais notas médias que os de escola pública, mostrandose, portanto, mais tolerantes que aqueles $\left(\chi^{2}=20,05 ; g l=1\right.$; $p=0)$. As meninas usaram significativamente mais notas altas que os meninos, mostrando-se, portanto, mais severas $\left(\chi^{2}=76,59 ; g l=1 ; p=0\right)$. Os meninos usaram mais notas baixas e médias que as meninas, mostrando-se mais indulgentes $\left(\chi^{2}=64,98 ; g l=1 ; p=0\right.$ para notas baixas e $\chi^{2}=16,78 ; g l=1 ; p=0$ para notas médias). Os alunos residentes em bairros de alta e média exclusão social usaram mais notas altas que os de bairros de média e alta inclusão social $\left(\chi^{2}=42,79 ; g l=1 ; p=0\right)$; estes, por sua vez, mostraram-se mais indulgentes que aqueles, usando mais notas médias $\left(\chi^{2}=74,62 ; g l=1 ; p=0\right)$. Quanto à ocupação dos pais, constatamos que os alunos cujos pais são de profissões

A e B mostraram-se significativamente mais indulgentes, usando mais notas baixas e médias que os filhos de pais com profissões $\mathrm{C}$ e $\mathrm{D}$, que usaram mais notas altas que os anteriores (para notas baixas, $\chi^{2}=9,17 ; g l=1 ; p=0,0025$; para notas médias, $\chi^{2}=53,44 ; g l=1 ; p=0$; para notas altas, $\chi^{2}=8,54$; $g l=1 ; p=0,0035$ ). Finalmente, os indivíduos $\mathrm{sim} / \mathrm{sim}$ (mais tolerantes com relação à possibilidade de leis serem modificadas e de existir uma situação em que leis podem ser

Tabela 3

Número e Porcentagem de Notas Baixas, Médias e Altas dadas às Infraçoes pelas Subpopulações os Alunos

\begin{tabular}{lcccccc}
\hline Sub populações & \multicolumn{7}{c}{ Notas } \\
& Notas 0 e 2 - Baixas & Notas 4 e 6 - Média & \multicolumn{2}{c}{ Nota 8 e 10 - Altas } \\
\hline Particular & 140 & $6,48 \%$ & 351 & $16,24 \%$ & 1670 & $77,28 \%$ \\
Pública & 537 & $8,43 \%$ & 791 & $12,42 \%$ & 5043 & $79,16 \%$ \\
Meninos & 423 & $10,42 \%$ & 608 & $14,98 \%$ & 3027 & $74,59 \%$ \\
Meninas & 254 & $5,68 \%$ & 534 & $11,94 \%$ & 3686 & $82,39 \%$ \\
Bairro 1 e 2 & 328 & $8,13 \%$ & 407 & $10,09 \%$ & 3297 & $81,77 \%$ \\
Bairro 3 e 4 & 315 & $7,54 \%$ & 694 & $16,62 \%$ & 3167 & $75,84 \%$ \\
Ocupapai A e B & 134 & $6,41 \%$ & 361 & $17,27 \%$ & 1595 & $76,32 \%$ \\
Ocupapai C e D & 471 & $8,55 \%$ & 662 & $12,02 \%$ & 4375 & $79,43 \%$ \\
Indivíduos não/não & 89 & $7,09 \%$ & 126 & $10,04 \%$ & 1040 & $82,87 \%$ \\
Indivíduos sim/sim & 192 & $7,71 \%$ & 390 & $15,67 \%$ & 1907 & $76,62 \%$ \\
\hline
\end{tabular}

Os alunos da escola pública usaram, tanto como os de escola particular, a grande maioria de notas altas; no entanto, também usaram mais notas baixas que os de escola particular (para notas baixas, $\chi^{2}=8,14 ; g l=1 ; p=0,0043$ ), mostrando, embora de forma muito moderada, a tendência à bipolaridade que Malewska e Walgrave (1983) encontraram nos adolescentes em geral, quando comparados com os adultos e, os menores infratores quando comparados com outros

\footnotetext{
${ }^{6}$ Teste para igualdade de proporções entre duas amostras com correção de continuidade baseado na estatística de teste Qui-Quadrado. As diferenças foram consideradas significativas para $p$-valor abaixo de 0,05.
}

desobedecidas, tal como visto em Menin, 2000b) usaram, significativamente, mais notas médias e menos notas altas que os indivíduos não/não $\left(\chi^{2}=21,77 ; g l=1 ; p=0\right.$ para notas médias; e $\chi^{2}=19,08 ; g l=1 ; p=0$, para notas altas).

A Figura 1 mostra as mesmas subpopulações dos adolescentes e sua localização espacial em função de como se distribuem em relação ao uso diferencial das notas agrupadas em três categorias: baixas ( 0 e 2$)$, médias (4 e 6 ) e altas (8 e 10). Para construí-la foi utilizada uma análise de correspondência que permite estudar como diferentes variáveis, no caso, as subpopulações dos alunos e as médias de notas dadas às infrações, se relacionam entre si. 


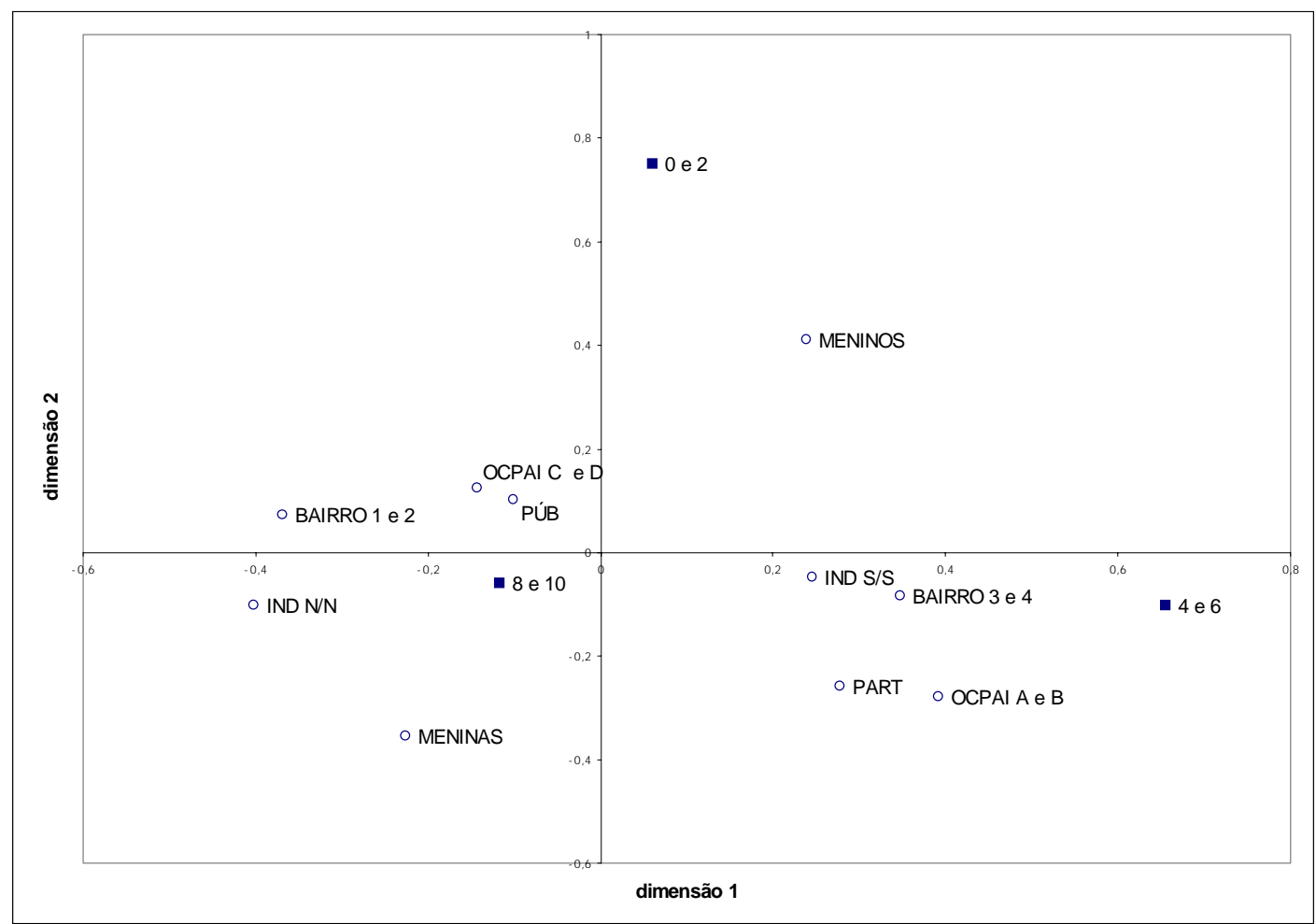

Figura 1. Uso das notas baixas, médias e altas nas subpopulações de alunos.

$\mathrm{Na}$ Figura 1 os dados foram tratados de modo Canonical (SPSS, 1990) onde as distâncias dos pontos das linhas e das colunas são igualmente considerados e nela se pode interpretar que quanto mais próximas estão as variáveis no espaço, mais associam-se entre si, o que pode indicar similaridade, afinidade ou interação entre as variáveis estudadas (Greenacre, 1993). Pode-se notar que, embora o uso das notas entre os alunos tenha sido muito semelhante, os indivíduos Sim/sim, os alunos de bairros de alta e média inclusão estão do lado das notas medianas, 4 e 6; os meninos, mais acima à direita são os mais social, os alunos das escolas particulares e os filhos de pais com profissões de maior status próximos das notas mais baixas, 0 e 2 e as meninas, os indivíduos Não/não, os alunos de bairros de alta e média exclusão social, os de escolas públicas e de ocupações C e D aproximam-se, mais que outras subpopulações, das notas altas.

\section{Considerações Finais}

Os resultados apontam diferenças significativas com relação à severidade ou tolerância nos julgamentos dos jovens e diferenças qualitativas com relação às infrações que os adolescentes consideram como mais graves. Três agrupamentos mais se opõem: os meninos das meninas, os adolescentes de classe socio-econômica alta dos de classe baixa, os indivíduos tolerantes com relação a mudança nas leis e sua desobediência ocasional dos intolerantes. Considerando como Doise (1994) que as representações sociais são sempre tomadas de posição simbólicas que podem organizar-se de diversas formas segundo se imbriquem em relações sociais diferentes e que os julgamentos que as pessoas exibem sobre condutas, enunciados ou crenças sociais são sempre atos sociais que se inscrevem na dinâmica total de um campo social, podemos considerar as diferentes tomadas de posição das subpopulações de adolescentes sobre as infrações como representações comuns a certos subgrupos: os meninos, os mais ricos, os mais tolerantes. E, além disso, podemos considerar tais representações como "re-apresentaçoes" do real que servem a interesses, necessidades, desejos de cada grupo. Nesse caso, como afirma Jodelet (1994) um mesmo objeto pode sofrer, nas suas representações, distorções, suplementações ou supressões em relação às suas características. As variações entre grupos, principalmente quando subdivididos em classes sócio-econômica alta ou baixa, sugerem que, mais do que estágios de desenvolvimento moral ou cognitivo, vivências de classe podem determinar a forma como as infrações são consideradas. Tal como certos autores vem apontando (Souza, 1999), nossa história cultural e política pode bem explicar por que nas classes mais favorecidas a desobediência à lei e suas infrações, pode ser analisada de forma mais tolerante e maleável e porque nas classes menos favorecidas de forma rígida. Assim, diferenças 
de representações entre grupos podem indicar mais do que atrasos ou evoluções no desenvolvimento do julgamento social; podem evidenciar fortes marcações sociais fruto da continuidade, por gerações, de distintas práticas e concepções sobre esse objeto social que é a lei e seus derivados.

\section{Referências}

Doise, W. (1991). Laperception des droits de l'homme dans lasocieté contemporaine (Rapport final, Vol. 1). Paris: Centre de Education de la vie politique française de l'Institut de droit compare de L'Université de Paris.

Doise, W. (1994). Attitudes et représentations sociales. Em D. Jodelet (Org.), Les représentations sociales (pp.220-238). Paris : Presses Universitaires de France.

Doise,W., Clémence, A., Rosa, A. S. \& Gonzales, L. (1995). La représentation sociale des droits de l'homme: Une recherche internationale sur l'éntendue et les limites de l'universalité. Journal International de Psychologie, 30(2), 181-212.

Greenacre, M. J. (1993). Correspondence analysis in practice. New York: Academic Press.

Jodelet, D. (1994). Représentations sociales: Un domaine en expansion. Em D. Jodelet (Org.), Les représentations sociales (pp.31-62). Paris: Presses Universitaires de France.

Kohlberg, L. (1992). Psicologia del desarrollo moral. Bilbau: Biblioteca de Psicologia, Desclée de Brouwer.
Malewska, H. \& Walgrave, L. (1983). Approche theorique et methodologique. Em J. P. Bonerandi \& cols. (Org.), Délits des jeunes et jugement social (pp. 5-34). Paris. Fondation de la Maison des Sciences de L'Homme.

Malewska, H., Peyre, V. \& Bonerandi, J. P. (1979). Attitudes envers les delits des jeunes eux-memes (Collections Enquêtes et recherches, Vol. 12). Vancresson, France.

Menin, M. S. S. (2000a). Representações sociais de justiça em adolescentes infratores: Discutindo novas possibilidades de Pesquisa. Psicologia: Reflexão e Crítica, 13, 59-72.

Menin, M. S. S. (2000b). Representacõoes sociais de lei, crime e injustica em adolescentes. Tese de Livre-docência, Faculdade de Ciências e Tecnologia, Universidade Estadual Paulista. Presidente Prudente, São Paulo.

Moscovici, S. (1978). A representação social da Psicanálise. Rio de janeiro: Zahar Editores. (Original publicado em 1961)

Piaget, J. (1977). O julgamento moral da criança. São Paulo: Mestre Jou. (Original publicado em 1932)

Souza, M. (1999). A experiência da lei e a lei da experiência: Ensaios sobre práticas sociais e subjetividades no Brasil. Rio de Janeiro: Revan; São Paulo: FAPESP.

Recebido: 28/01/2002

$1^{a}$ revisão: $21 / 05 / 2002$

Última revisão: 08/08/2002

Aceite final: 27/08/2002

Sobre a autora

Maria Suzana De Stefano Menin é Professora Livre-docente em Psicologia da Educação do

Departamento de Educação da Universidade Estadual Paulista de Presidente Prudente. 
Anexo A

Tabela 1.1

Valores de Desvio-padrão das Médias de Notas dadas às Infraçōes Dentro de Cada Subpopulação de Alunos

Infrações

Usar craque ou cocaína

Matar para roubar

Furtar toca-fitas

Maltratar criança

Roubar blusão de loja

Uma adolescente se prostituir

Matar alguém numa briga

Usar maconha

Fazer aborto

Riscar a pintura de um carro

Destruir carteira escolar

Cortar banco de ônibus

Agredir colega

Xingar professora

Dirigir s/ carta

Matar menino assaltante

Falsificar documento

Policial ferir alguém
Subpopulações

\begin{tabular}{|c|c|c|c|c|c|c|c|c|c|}
\hline 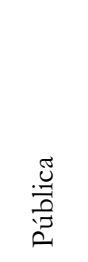 & 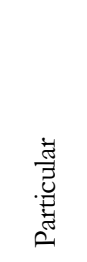 & 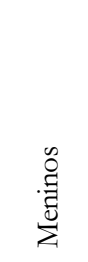 & 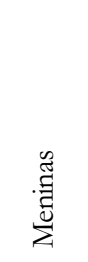 & 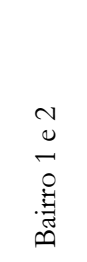 & 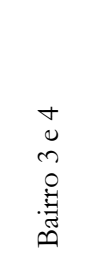 & 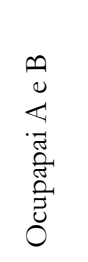 & $\begin{array}{l}0 \\
0 \\
\cup \\
. \tilde{J} \\
\tilde{\tilde{I}} \\
\tilde{ت} \\
0 \\
0\end{array}$ & 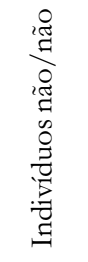 & 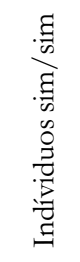 \\
\hline 1,76 & 1,72 & 2,13 & 1,26 & 1,71 & 1,82 & 1,44 & 1,91 & 1,35 & 1,55 \\
\hline 2,01 & 1,67 & 2,43 & 1,28 & 1,89 & 2,04 & 1,42 & 2,12 & 2,15 & 1,85 \\
\hline 1,92 & 1,66 & 2,10 & 1,59 & 2,02 & 1,74 & 1,55 & 1,95 & 1,82 & 1,97 \\
\hline 2,09 & 1,69 & 2,33 & 1,62 & 1,90 & 2,11 & 1,65 & 2,15 & 1,51 & 1,89 \\
\hline 2,03 & 1,61 & 2,31 & 1,45 & 1,75 & 2,01 & 1,55 & 1,96 & 1,45 & 1,95 \\
\hline 2,14 & 1,94 & 2,53 & 1,48 & 2,02 & 2,16 & 2,02 & 2,15 & 1,75 & 2,14 \\
\hline 2,09 & 1,99 & 2,47 & 1,53 & 2,00 & 2,06 & 1,73 & 2,13 & 1,91 & 1,80 \\
\hline 2,53 & 2,50 & 2,80 & 2,20 & 2,42 & 2,62 & 2,53 & 2,42 & 2,24 & 2,62 \\
\hline 2,46 & 3,10 & 3,08 & 2,22 & 2,49 & 2,88 & 3,06 & 2,50 & 2,53 & 3,06 \\
\hline 2,48 & 2,02 & 2,52 & 2,24 & 2,52 & 2,22 & 1,96 & 2,47 & 2,05 & 2,47 \\
\hline 2,76 & 2,78 & 2,94 & 2,58 & 2,80 & 2,69 & 2,62 & 2,88 & 2,70 & 2,74 \\
\hline 2,83 & 2,31 & 2,99 & 2,42 & 2,88 & 2,57 & 2,28 & 2,88 & 2,66 & 2,50 \\
\hline 2,52 & 2,26 & 2,60 & 2,24 & 2,58 & 2,34 & 2,26 & 2,50 & 2,08 & 2,56 \\
\hline 2,79 & 2,35 & 2,97 & 2,36 & 2,71 & 2,69 & 2,34 & 2,82 & 2,41 & 2,67 \\
\hline 2,86 & 2,91 & 3,12 & 2,62 & 2,75 & 2,95 & 2,77 & 3,01 & 2,92 & 2,82 \\
\hline 3,07 & 2,69 & 3,27 & 2,67 & 2,93 & 2,98 & 2,96 & 2,99 & 3,07 & 3,06 \\
\hline 3,18 & 3,22 & 3,32 & 3,08 & 3,14 & 3,18 & 3,09 & 3,18 & 3,17 & 3,22 \\
\hline 3,37 & 2,91 & 3,44 & 3,07 & 3,37 & 3,04 & 2,86 & 3,38 & 3,53 & 3,11 \\
\hline
\end{tabular}




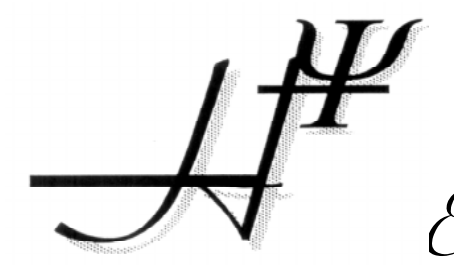

Epistemologia e Historia de Psicologia

Um núcleo voltado ao estudo dos fundamentos conceituais da psicologia, à pesquisa historiográfica e ao ensino da história da psicologia em cursos de graduação.

Prof. William B. Gomes

Curso de Pós-Graudacão em Psicologia

Instituto de Psicologia da Universidade federal do Rio Grande do Sul

Rua Ramiro Barcelos 2600

90035.003 Porto Alegre - RS

E-mail: gomesw@ufrigs.br. 